\title{
Effect of Vermicompost Doses on Canabis Sativa Photosynthesis-Related Parameters, Growth and Yield
}

\author{
Veneranda Stramkale \\ Institute of Agricultural Resources \\ and Economics \\ Struktoru iela 14, Rīga, Latvia \\ veneranda.stramkale@arei.lv \\ Agnese Kirse \\ Faculty of Biology \\ University of Latvia \\ Jelgavas iela 1, Rīga, Latvia
}

\author{
Gederts Ievinsh \\ Faculty of Biology \\ University of Latvia \\ Jelgavas iela 1, Rīga, Latvia
}

Ieva Kroica

Institute of Agricultural Resources

and Economics

Struktoru iela 14, Rīga, Latvia

\author{
Māra Vikmane \\ Faculty of Biology \\ University of Latvia \\ Jelgavas iela 1, Rīga, Latvia
}

Abstract - Hemp, Cannabis sativa is certainly a multifunctional as well as a niche crop, due to great potential for innovative use of its different products. Aspects of hemp mineral nutrition are very important in the cultivation of these plants, in particular to make cultivation environmentally friendly by replacing synthetic fertilizers with organic ones. Among organic fertilizers, vermicompost has gained particular attention within the last decades. Explaining the role of vermicompost, this study evaluated the effects of different doses of this fertilizer on hemps in two separate field studies. In a small-scale field experiment, the effect of two doses of vermicompost and adequate concentrations of mineral elements fertilizers the growth, physiological condition, as well as yield of hemp was compared. The effect of increasing doses of vermicompost on the physiological condition and yield of hemp was analysed in a broader field experiment. The experiments were performed at the Vilianni Scientific Centre of the Agricultural Resources and Economics, in 2017 and 2018, using the Latvian hemp cultivar 'Pūriņi'. For the experiments, certified vermicompost produced by 'Eko Zeme' (Latvia) was used, which was produced from composted cow manure by adding grass biomass. In field experiment, the positive effect of vermicompost on hemp growth was greater than the effect of equivalent mineral fertilizer concentrations. When using vermicompost in increasing doses, better hemp growth (40-60\%) was observed at 5 and $10 \mathrm{t} \mathrm{ha}^{-1}$, stem yield increased on average by $40 \%$ due vermicompost, seed yield ranging from $1.00 \mathrm{tha}^{-1}$ in control plants, to $1.56 \mathrm{t} \mathrm{ha}^{-1}$ in 20 $\mathrm{t} \mathrm{ha}^{-1}$ in plants treated with $20 \mathrm{t} \mathrm{ha}^{-1}$ vermicompost plants. The weight of 1000 seeds per plant in all variants (from 13.54 to 13.85 g) was relatively close to the indicated maximum level (14.59 g). A statistically significant increase in chlorophyll concentration in plant leaves was observed under the influence of vermicompost. The increase in the Performance Index of the chlorophyll $a$ fluorescence measurement was only for plants in individual experimental variants; regardless of how significant the increase in stem and seed yield was due to the respective doses of vermicompost. In general, the results characterize the growth of hemp in local agroclimatic conditions and allow to expect a stable increase in yield under the influence of vermicompost.

Keywords - chlorophyll a fluorescence, bio-humus, plant growth, stem and seed yield.

\section{INTRODUCTION}

Cultivars of Cannabis sativa L., grown for both fiber and seed, are known as hemp, and have been traditionally cultivated since early years of agriculture [31]. Currently hemp is characterized as a multipurpose or even a niche crop due to large potential in different innovative applications. Biology, and uses and cultivation techniques of hemp have been thoroughly reviewed recently [3], [4]. More recent reviews on other important aspects of hemp cultivation emphasize large scientific and practical interest on this crop [17], [21].

Modern trends in agrobiological studies of hemp show that aspects of mineral nutrition still prevail [20], [28] followed by comparison of suitability of different hemp

\section{Online ISSN 2256-070X


Veneranda Stramkale, et al. Effect of Vermicompost Doses on Canabis Sativa Photosynthesis-Related Parameters,

Growth and Yield

genotypes over different cultivation conditions [1], [7], [22], [29] and resistance to environmental constraints, like temperature [28] and soil salinity [12]. A recent metaanalysis of yield-determining factors of $C$. sativa provided further evidence that complex of abiotic factors (most importantly, light and fertilization) together with genotype and performed agronomic techniques (most importantly, plant density) jointly affect plant yield [6].

In respect to mineral nutrition of hemp, mainly effect of nitrogen has been studied so far [17], [18], [20], [26], [28], supporting the nitrophilous status of the crop [25]. However, due to growing concerns for environment protection and increased agricultural sustainability, more environment-friendly means of fertilization needs to be proposed and approved also for hemp production. As a reasonable alternative to application of soluble inorganic nutrients, balanced use of organic fertilizers not only results in remarkable plant production with less environmental contamination but also provides significant increase in soil sustainability [30].

Among organic fertilizers, vermicompost has gained particular attention within the last decade. Vermicompost is produced by a coordinated action of earthworms and their symbiotic organisms from organic waste, resulting in production of stabilized peat-like material with fine structure and high porosity [11]. In general, vermicompost application results in increased physiological performance and growth of cultivated plants (reviewed by [13]). One of beneficial effects of vermicompost application on plants is associated with increased supply of plant-available mineral nutrients in soil [16]. Another positive benefit of vermicompost application is due to additional effect of biologically active, plant hormone-like substances produced by microorganisms [10]. It has been found that both mechanisms are responsible for positive effects on plant growth and yield in vermicompost-amended soils [16], [14]. In the context of the present study, vermicompost extract has been shown to stimulate germination of hemp seeds due to summed activity of humic and fulvic acids, while linear growth stimulation of a plant hypocotyls was induced by some unidentified soluble compounds, but increase in fresh mass of the hypocotyls resulted from effect of mineral nutrients [15]. Consequently, there is a good reason to consider that hemp plants can benefit from application of vermicompost in field conditions as a result of stimulation at the level of both increased physiological performance and growth.

The aim of the present study was to evaluate effect of different vermicompost doses on hemp plants. Two separate experiments with vermicompost in natural conditions were performed, including small-scale field study and field study. The goal of the small-scale field experiment was to compare the effect of two doses of vermicompost with that of respective doses of mineral nutrients on growth, physiological status and yield of hemp plants. The goal of the field experiment was to analyse the effect of increasing doses of vermicompost on physiological status and yield of hemp.

\section{MATERIALS AND METHODS}

\section{Plant material and organic fertilizer}

Seeds of local hemp cultivar 'Pūrini' were obtained directly from growers and used in the present study. The same plant material has been successfully used in local agroclimatic conditions in the previous studies [18], [26].

Vermicompost (bio-humus, earthworm compost) used in both experiments was produced by 'Eko Zeme' (Latvia) from composted cow manure with addition of grass biomass, and was certified for organic farming according to the EU Council Regulation No. 889/2008. NPK ratio in vermicompost was 1.0-2.9-7.6, indicating high predominance of $\mathrm{K}$ and dominance of $\mathrm{P}$; with reasonable amount of other macro- and micronutrients except Mo (Table 1).

Field experiment was performed at Viḷāni Scientific Centre of Institute of Agricultural Resources and Economics in 2017 and 2018.

TABLE 1 CHARACTERISTICS OF SOIL USED IN SMALL-SCALE FIELD EXPERIMENT AND VERMICOMPOST USED IN BOTH EXPERIMENTS IN COMPARISON TO OPTIMUM LEVEL OF MINERALS FOR CULTIVATED PLANTS [19]. CONCENTRATION (mg L ${ }^{-1}$ DRY SUBSTRATE) OF PLANTAVAILABLE ELEMENTS WAS MEASURED IN $1 \mathrm{M}$ HCl EXTRACT. ECELECTRICAL CONDUCTIVITY

\begin{tabular}{|c|c|c|c|}
\hline Element & Soil & Vermicompost & $\begin{array}{l}\text { Optimum for } \\
\text { cultivated } \\
\text { plants }\end{array}$ \\
\hline $\mathrm{N}$ & 90 & 670 & 120 \\
\hline $\mathrm{P}$ & 218 & 1924 & 60 \\
\hline K & 300 & 5100 & 150 \\
\hline $\mathrm{Ca}$ & 840 & 12750 & 800 \\
\hline $\mathrm{Mg}$ & 195 & 3250 & 50 \\
\hline S & 11 & 213 & 50 \\
\hline $\mathrm{Fe}$ & 815 & 185 & 30 \\
\hline Mn & 165 & 120 & 1.5 \\
\hline Zn & 5.0 & 65 & 1 \\
\hline $\mathrm{Cu}$ & 2.7 & 7.0 & 0.5 \\
\hline Mo & 0.04 & 0.02 & 0.02 \\
\hline B & 0.1 & 2.9 & 0.2 \\
\hline $\mathrm{Na}$ & 0.003 & 0.17 & - \\
\hline $\mathrm{pH}_{\mathrm{KCl}}$ & 5.34 & 7.74 & - \\
\hline $\mathrm{EC}\left(\mathrm{mS} \mathrm{cm}^{-1}\right)$ & 0.49 & 18.4 & 一 \\
\hline
\end{tabular}

\section{Small-scale experiment in field conditions}

Due to legal restrictions to grow hemp indoor introduced in Latvia, experiments with hemp plants in controlled conditions, like vegetation pot study in greenhouse, are not possible. Therefore, initial screening of vermicompost effects in comparison to that of identical dose of mineral nutrient addition was performed as a smallscale experiment in soil in field conditions in 2017. 
Analysis of plant-available mineral nutrient concentration in the soil and vermicompost was performed in a certified agrochemical laboratory using $1 \mathrm{M} \mathrm{HCl}$ as an extractant. The soil was loamy sand (2\% organic matter content), slightly acidic, well balanced in respect to mineral nutrients, but with some shortage of N, S and B (Table 1; [19]).

Seeds were sown by hand in $1 \mathrm{~m}^{2}$ plots, 100 seeds per plot. Two doses of vermicompost $\left(0.5\right.$ and $\left.1.0 \mathrm{~kg} \mathrm{~m}^{-2}\right)$ were used, equivalent to 5 and $10 \mathrm{t} \mathrm{ha}^{-1}$. Mineral nutrients in amounts equivalent to these in respective vermicompost treatments were used for two mineral fertilizer treatments. As a non-treated control, soil with no added fertilizers was used. Four plots per treatment were used. Replicates were randomly distributed on site.

Plant height was measured four times during the vegetation period (2, 15, 29 July and 12 August) separately for female and male plants. Leaf chlorophyll content was measured by a chlorophyll meter SPAD-507 (KonicaMinolta, Japan). Ten plants per replicate were randomly selected, with three readings per plant on the major photosynthetically active leaves.

Experiment was terminated on 31 August for male plants and on 17 September for female plants. All plants in each plot were cut manually and seeds were separated. To measure dry mass weight, plant material was dried in a ventilated place to a constant air-dry mass.

\section{Field study}

Field experiment was performed at in 2018. Soil was humi-podzolic gley, with $8.1 \%$ organic matter content, $\mathrm{pH}$ 7.1, $\mathrm{P}_{2} \mathrm{O}_{5} 201 \mathrm{mg} \mathrm{kg}^{-1}, \mathrm{~K}_{2} \mathrm{O} 139 \mathrm{mg} \mathrm{kg}^{-1}$. The pre-crop was spring wheat, fertilized by Yara Mila NPK(S) 18-8-16(8), $300 \mathrm{~kg} \mathrm{ha}^{-1}$, and additional fertilization by $\mathrm{NH}_{4} \mathrm{NO}_{3} 330 \mathrm{~kg}$ $\mathrm{ha}^{-1}$. Soil tillage was performed in autumn followed by cultivation at the end of April.

Plot size was $2.0 \times 2.5 \mathrm{~m}$, with four replicates per treatment. Treatments were organized by a randomized block method. Seeds were sown on 11 May by means of sowing machine SN-16, with sowing rate $50 \mathrm{~kg} \mathrm{ha}^{-1}$.

Non-destructive physiological measurements were performed three times during the vegetation season, on 26 June, 23 July and 17 September. Ten plants per replicate were randomly selected and analysed, using the largest leaf from top of the individual plant. Leaf chlorophyll concentration was measured by a chlorophyll meter CCM300 (Opti-Sciences, USA). Chlorophyll a fluorescence was measured in dark-adapted, physiologically most active leaves by Handy PEA fluorometer (Hansatech Instruments, UK). Chlorophyll a fluorescence parameter total Performance Index was used for characterization of photochemical activity, combining three function-related (trapping of absorbed exciton, electron transport between the photosystems, reduction of end-electron acceptors) and one structure-related (antenna chlorophyll per reaction centre chlorophyll) parameters [27].
Climate variables (temperature and precipitation) were measured by an on-farm meteorological station Adcon connected to a computer program Dacom Plant Plus. According to the obtained data (Fig. 1A), average temperature values were relatively close to long-term values in 2017, with significantly warmer first decade of April, followed by somehow cooler temperatures through the rest of April and May. Precipitation level in May was only $29 \%$ from long-term average, but heavy rain occurred on the third decade of August (Fig. 1B). May and July in 2018 was relatively warm, with average temperature exceeding long-term values by 4.2 and $2.3^{\circ} \mathrm{C}$ (Fig. 1A). In contrast, precipitation level in May, beginning of June and July was lower than long-term average, but abundant rain was occurring at the end of June and in mid-August (Fig. 1B).

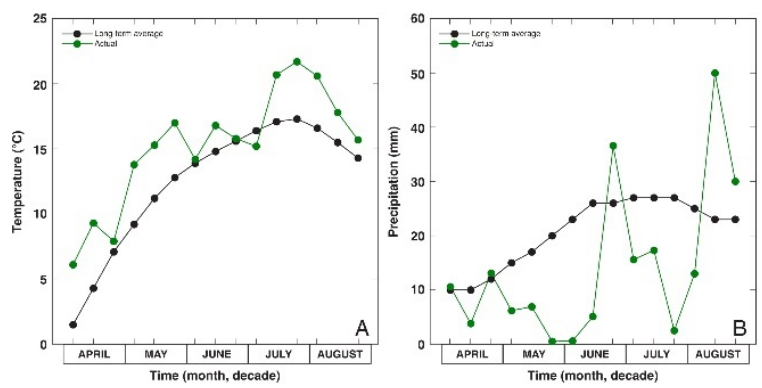

Fig. 1. Seasonal variation in local temperature (A) and summary precipitation (B) during the field study in 2018 as compared to longterm local average values.

Experiment was terminated on 19 September. All plants in $1 \mathrm{~m}^{2}$ area in the centre of each plot were cut manually. Seeds were separated and dried in an oven at 60 ${ }^{\circ} \mathrm{C}$. Harvested stems were dried in a ventilated place to determine the fibre content.

\section{Statistical analysis}

Data analysis was performed using KaleidaGraph (v. 4.1, Synergy Software). Student t-test was used to estimate statistically significant differences for morphological data between individual treatments $(p<0.5)$.

\section{RESULTS}

\section{Small-scale experiment in field conditions}

Both vermicompost and mineral fertilizer treatments resulted in significant stimulation of stem growth of hemp plants at both doses used (Fig. 2). Effect of vermicompost application on stem growth was significantly more pronounced than that of equivalent mineral dose. Relative intensity of stem growth stimulation in comparison to control plants became less pronounced later in the season. 


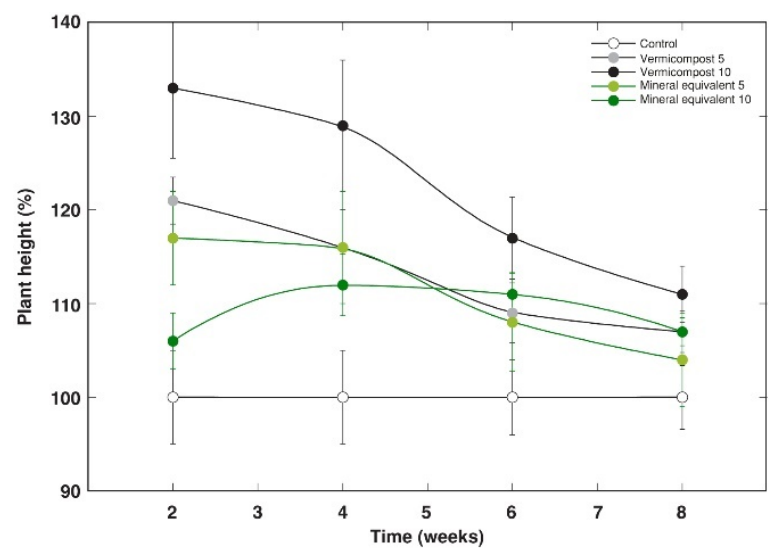

Fig. 2. Effect of increasing vermicompost rate or equivalent mineral nutrient application on changes in relative height of hemp plants in conditions of the small-scale field experiment. Results are means $\pm \mathrm{SE}$ from four replicates with ten individual measurements each.

Dry mass of vegetative above-ground parts of female hemp plants significantly increased in all fertilizer applications (Fig. 3A). There was a tendency that vermicompost treatment resulted in higher mass increase in comparison to that by equivalent mineral fertilizer, but the effect was not statistically significantly different. Also, there was no significant difference between the two doses of either vermicompost or mineral fertilizer. Dry mass accumulation in vegetative aboveground parts of male hemp plants was also significantly stimulated by both doses of vermicompost application, but to a lesser extent than that for female plants (Fig. 3B). Application of mineral fertilizer at $5 \mathrm{t} \mathrm{ha}^{-1}$ equivalent dose had no significant effect on dry mass of male plants, but there was a statistically significant mass increase at $10 \mathrm{t} \mathrm{ha}^{-1}$ equivalent mineral fertilizer dose, which was even higher than that of respective vermicompost treatment. Similarly, seed mass per plant significantly increased in hemp plants under both vermicompost doses, with significantly more pronounced effect at $5 \mathrm{t} \mathrm{ha}^{-1}$ (Fig. 3C). Equivalent mineral nutrient dose had significant effect on seed mass only for $10 \mathrm{t} \mathrm{ha}^{-1}$ treatment.

Leaves of female plants had significantly higher chlorophyll concentration in comparison to that in male plants (Fig. 4). No significant differences in chlorophyll concentration were caused by any of the treatments.

\section{Field study}

In field conditions, vermicompost application resulted in significantly increased stem yield (Fig. 5A) as well as seed yield (Fig. 5B) of hemp plants at all doses. However, while seed yield significantly increased with increasing vermicompost dose, stem yield increase with vermicompost concentration was significant only up to 10 $\mathrm{t} \mathrm{ha} \mathrm{a}^{-1}$ and further increase was not significant. Mass of 1000 seeds was rather constant up to $10 \mathrm{t} \mathrm{ha}^{-1}$ vermicompost applications, and significantly increased only at $20 \mathrm{t} \mathrm{ha}^{-1}$ (Fig. 5C). In contrast, relative fibre content tended to decrease in vermicompost-treated plants (both female and male) in comparison to control plants, but the effect was not statistically significant (Fig. 5D).

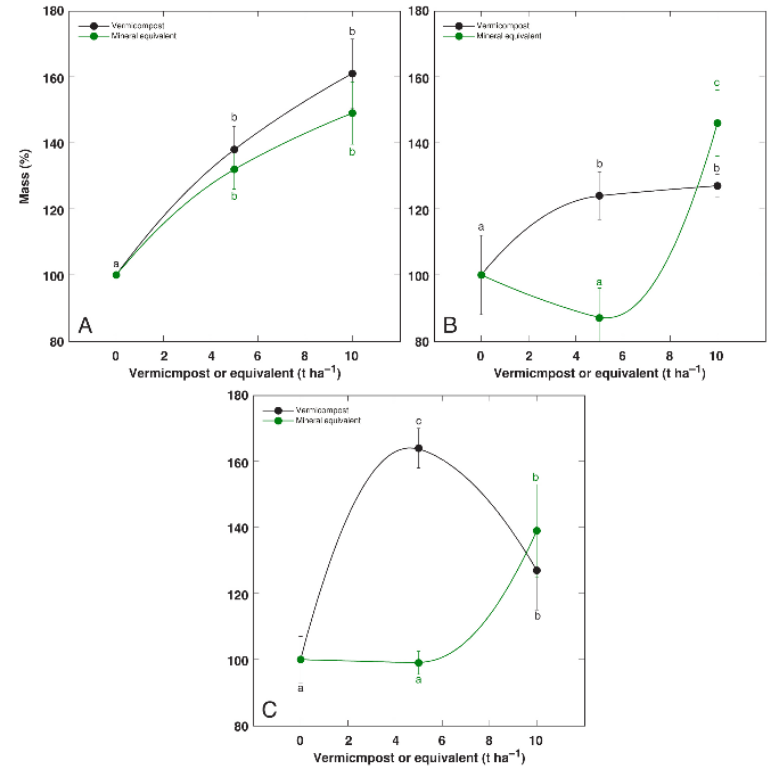

Fig. 3. Effect of increasing vermicompost rate or equivalent mineral nutrient application on relative dry mass of vegetative parts of female plants (A), male plants (B) and seed mass per plant (C) during the small-scale field experiment. Results are means \pm SE from four replicates. Values indicated by the same letters do not show statistically significant differences $(p<0.05)$.

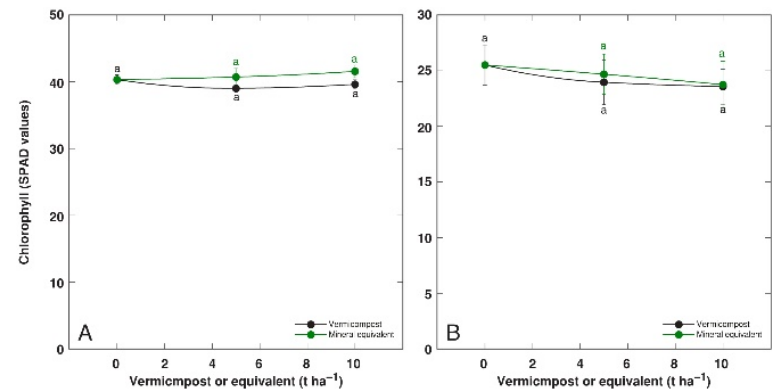

Fig. 4. Effect of increasing vermicompost rate or equivalent mineral nutrient application on leaf chlorophyll concentration of female (A) and male (B) hemp plants in conditions of the small-scale field experiment.

Results are means \pm SE from four replicates with ten individual measurements each. Values indicated by the same letters do not show statistically significant differences $(p<0.05)$.

Both leaf chlorophyll concentration and chlorophyll a fluorescence parameter Performance Index showed similar significant variations during vegetation season (Fig. 6). Both parameters increased from 26 June to 23 July, and decreased further to 17 September. Statistically significant increase of chlorophyll concentration in hemp plants was evident only for $5 \mathrm{t} \mathrm{ha}^{-1}$ treatment on 26 June and for $10 \mathrm{t}$ $\mathrm{ha}^{-1}$ treatment on 17 September (Fig. 6A). Statistically significant increase of Performance Index in hemp plants occurred only on 26 June for all vermicompost treatments independently on the applied concentration (Fig. 6B). 

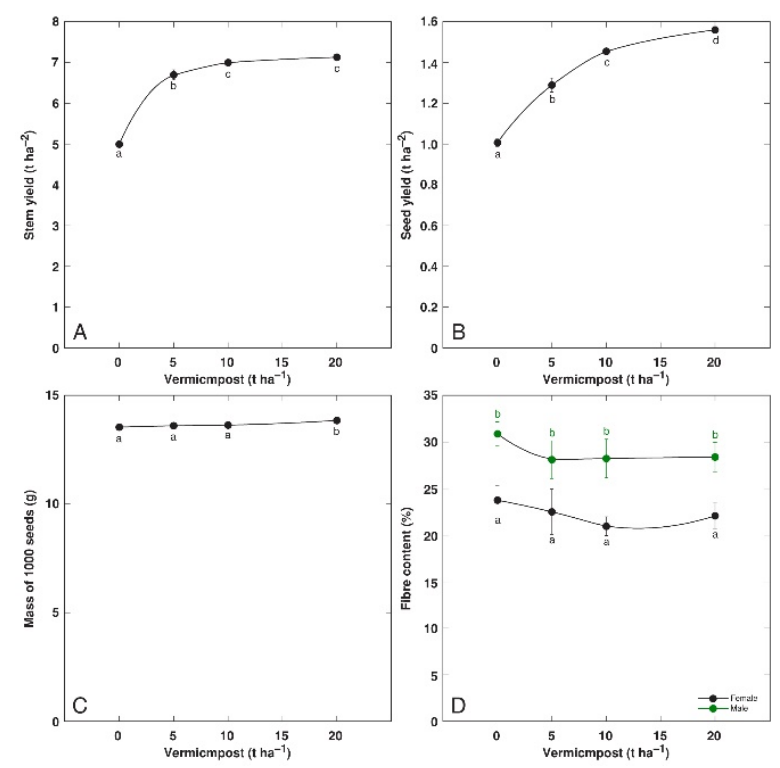

Fig. 5. Effect of increasing vermicompost application rate on stem yield (A), seed yield (B), mass of 1000 seeds (C) and fiber content (D) of hemp plants in conditions of the field experiment. Results are means \pm SE from four replicates. Values indicated by the same letters do not show statistically significant differences $(p<0.05)$.
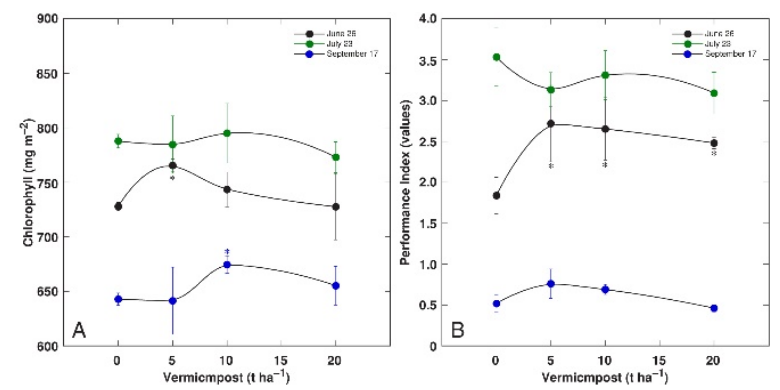

Fig. 6. Effect of increasing vermicompost application rate on leaf chlorophyll concentration (A), and chlorophyll $a$ fluorescence parameter Performance Index (B) of hemp plants in conditions of the field experiment. Results are means \pm SE from four replicates with ten independent measurements each. Values indicated by asterisks are statistically significantly different from the respective control value ( $p<$ 0.05).

\section{DISCUSSION}

As far as mineral nutrition of hemp plants is considered, mainly nitrogen fertilization effects have been studied so far [1], [17], [18] [20], [28]. In contrast, vermicompost as a form of organic fertilizer contains significantly higher proportion of plant-available $\mathrm{P}$ and $\mathrm{K}$ (Table 1). In a conditions of a small-scale field experiment, positive effect of vermicompost amendment on growth of hemp plants was significantly higher than that of equivalent mineral nutrient dose (Fig. 2 and 3), indicating that other constituents of vermicompost in addition to plant-available mineral nutrients were responsible for the effect. Plant physiology-related benefits of vermicompost application have been recently reviewed in detail [14], and it was concluded that most likely ingredients of vermicompost with putative growth-promoting effect could be soluble humic substances and microorganism-derived plant hormone-like compounds. We have shown previously that stimulation of hemp seed germination by vermicompost extract was due to summed activity of humic and fulvic acids, linear growth of hypocotyl and radicle was promoted by hormone-like substances, but mass accumulation in seedlings was promoted by plantavailable minerals [15].

When comparing both performed experiments, it is evident that increase in plant dry mass due to vermicompost amendment was by $60 \%$ in the small-scale field experiment (Fig. 3A), but only by $40 \%$ in the field experiment (Fig. 5A). One of the reasons for this discrepancy could be differences in soil characteristics between the two sites. In a soil with relatively high organic matter content, similar to conditions of the field experiment performed in the present study, humic substances in vermicompost amendment would probably have a small effect in stimulating hemp plant growth. One can also need to consider differences in climatic conditions for the respective site of particular experiment and the year, but particular climatic conditions were not registered during the small-scale experiment. However, as it was evident from climate data recorded in the Vilāni station, season of 2017 was significantly cooler than that of 2018, especially, in June and July. Relatively small amount of precipitation during early seedling growth in May in both years evidently negatively affected hemp plant germination and initial development, but general positive effect of vermicompost in 2018 could be related to further periods of low precipitation. It has been shown previously that vermicompost amendment can protect plants and increase their yield in conditions of water shortage [2].

In respect to other yield components, stem yield under field conditions increased on average by $40 \%$ due to vermicompost, seed yield in the present study varied from $1.00 \mathrm{t} \mathrm{ha}^{-1}$ in control plants up to $1.56 \mathrm{t} \mathrm{ha}^{-1}$ in plants treated with $20 \mathrm{t} \mathrm{ha}^{-1}$ vermicompost (Fig. 5B), which is within the four-year annual seed yield range of this cultivar in the local conditions when no additional nitrogen fertilizer is supplied (0.83 to $1.60 \mathrm{t} \mathrm{ha}^{-1}$-[26]). Mass of 1000 seeds (13.54 to $13.85 \mathrm{~g}$ ) was relatively close to maximum level reported (14.59 g) for the particular cultivar even with additional nitrogen fertilizer [26]. Consequently, results of the present study adequately reflect typical performance of hemp plants in local agroclimatic conditions, and stable increase of yield parameters by vermicompost amendment can be predicted.

Increased physiological performance is an extremely important aspect of plant growth stimulation. It is evident that in order to sustain increased biosynthetic and energetic needs of a plant individual during enhanced growth, an adequate level of photosynthetic activity needs to be maintained. Therefore, photosynthesis-related parameters such as leaf chlorophyll concentration and chlorophyll $a$ fluorescence indices, which reflect energy flow during photochemical reactions, have been widely used for characterization of physiological status of plants both in respect to environmental variables as well as agro-climatic factors [5], [15]. In particular, in experiments with nitrogen 
fertilization of hemp plants, it was shown that different aspects of photosynthesis are differentially affected by increased nitrogen availability [18]. While it is usually thought that increased leaf chlorophyll concentration always reflects nitrogen concentration [9], [23], in hemp leaves this parameter was only approximate indication of their nitrogen content. However, activity of photochemical reactions of photosynthesis increased in a concentrationdependent manner due to increased nitrogen availability [18]. For example, stimulation of photosynthetic performance of hemp plants by increased doses of nitrogen without growth stimulation is thought to be due to redistribution of nitrogen to synthesis of ribulose 1,5biphosphate carboxylase protein, resulting in increased photosynthetic performance [24]. Similarly, in the case of vermicompost application, improvement of metabolism in vermicompost-treated plants was partially independent on growth-related effects [13].

Factors, stimulating plant growth, not always show metabolic stimulation and increased physiological performance of plants and vice versa. Increase of chlorophyll concentration in cotyledons of germinated seedlings of hemp as a result of vermicompost treatment has been shown to be a direct general response, mainly associated with effect of humic acid [15]. In field conditions, this effect can be greatly masked by fluctuations in different soil- and climate-related factors, as shown also in the present study in the experiment in small-scale field conditions, where there were no changes in leaf chlorophyll concentration (Fig. 4) of vermicompost-treated hemp plants despite significant stimulation of their growth (Fig. 2 and 3). In field conditions, vermicompost-related statistically significant increase in leaf chlorophyll concentration (Fig. 6A) and chlorophyll a fluorescence parameter Performance Index (Fig. 6B) was evident only in plants for separate treatments and/or dates irrespective of significant stimulation of stem (Fig. 5A) and seed yield (Fig. 5B) by all applied vermicompost doses.

It can be concluded that soil amendment with vermicompost is a promising technique to increase both hemp seed and fibre yield when using dual purpose hemp cultivars, similar to cultivar 'Pūrini' used in this study, in conditions of temperate agriculture. Further studies are clearly necessary to promote integration of vermicompost use with other agrotechnical measures as well as to understand different aspects of yield quality as affected by organic amendments of this multipurpose crop.

\section{CONCLUSIONS}

1) Vermicompost 'Eko Zeme' application 5 and $10 \mathrm{t}$ $\mathrm{ha}^{-1}$ resulted in better hemp plant 'Pūrini' growth, in comparison to that of equivalent mineral nutrient dose.

2) Under the influence of vermicompost the dry weight of plants increased (40-60\%), stem and seed yield, 1000 seed weight.

3) There was a statistically significant increase in the concentration of chlorophyll in hemp leaves associated with vermicompost. However, the parameters characterizing photosynthesis under field conditions were relatively weak.

4) On the basis of our experiments soil amendment with vermicompost may be a promising technique to increase both hemp seed and fibre yield, when cultivating multipurpose hemp

\section{ACKNOWLEDGEMENTS}

Authors thanks Arturs Stalažs for his help with manuscript layout preparation.

\section{REFERENCES}

[1] A. Adamovičs, S. Ivanovs and V. Stramkale, "Investigations about the impact of norms of the fertilisers and cultivars upon the crop capacity biomass of industrial hemp", Agron. Res., vol. 14, pp. 641-649, 2016. https://doi.org/10.15159/ar.17.002

[2] D. Akhzari and M. Pessarakli, "Effects of vermicompost and urea fertilizers on qualitative and quantitative characteristics of Vetiveria zizanioides Stapf. grown under drought stress conditions", J. Plant Nutr., vol. 40, pp. 2063-2075, 2017. https://doi.org/10.1080/01904167.2017.1346126

[3] S. Amaducci, M. Colauzzi, G. Bellochi, S. L. Cosentino, K. Pahkala, T. J. Stomph, W. Westerhuis, A. Zatta and G. Venturi, "Evaluation of a phenological model for strategic decisions for hemp (Cannabis sativa L.) biomass production across European sites", Industr. Crops Prod., vol. 37, pp. 100-110, 2012. https://doi.org/10.1016/j.indcrop.2011.11.012

[4] S. Amaducci, D. Scordia, F. H. Liu, Q. Zhang, H. Guo, G. Testa and S. L. Cosentino, "Key cultivation techniques for hemp in Europe and China", Industr. Crops Prod., vol. 68, 2-16, 2015. https://doi.org/10.1016/j.indcrop.2014.06.041

[5] U. Andersone, I. Druva-Lūsīte, B. Ievina, A. Karlsons, J. N̦ečajeva, I. Samsone and G. Ievinsh, "The use of nondestructive methods to assess a physiological status and conservation perspectives of Eryngium maritimum L.", J. Coastal Conserv., vol. 15, pp. 509522, 2011. https://doi.org/10.1007/s11852-010-0139-7

[6] R. Backer, T. Schwinghamer, P. Rosenbaum, V. McCarty, S. E. Bilodeau, D. Lyu, M. B. Ahmed, G. Robinson, M. Lefsrud, O. Wilkins and D. L. Smith, "Closing the yield gap for Cannabis: a meta-analysis of factors determining Cannabis yield", Front. Plant Sci., vol. 10, article 496, 2019. https://doi.org/10.3389/fpls.2019.00495

[7] M. Baldini, C. Ferfuia, F. Zuliani and F. Danuso, "Suitability assessment of different hemp (Cannabis sativa L.) varieties to the cultivation environment", Industr. Crops Prod., vol. 143, article 111860, 2020. https://doi.org/10.1016/j.indcrop.2019.111860

[8] J. C. Callaway, "Hempseed as a nutritional resource: an onerview", Euphytica, vol. 140, pp. 65-72, 2004 https://doi.org/10.1007/s10681-004-4811-6

[9] R. H. Fox and C. L. Walthall, "Crop monitoring technologies to assess nitrogen status" in Nitrogen in Agricultural Systems, J. S. Schepers and W. R. Raun, Eds. Madison: ASA-CSSA-SSSA, 2008, pp. 647-674. https://doi.org/10.2134/agronmonogr49.c16

[10] L. Grantina-Ievina, U. Andersone, D. Berkolde-P̄̄re, V. Nikolajeva and G. Ievinsh, "Critical tests for determination of microbiological quality and biological activity in commercial vermicompost samples of different origins", Appl. Microbiol. Biotechnol., vol. 97, pp. 10541-10554, 2013. https://doi.org/10.1007/s00253-013-4825$\mathrm{X}$

[11] K. Huang, F. Li, Y. Wei, X. Fu and X. Chen, "Effects of earthworms on physicochemical properties and microbial profiles during vermicomposting of fresh fruit and vegetable wastes", Bioresour. Technol., vol. 170, pp. 45-52, 2014. https://doi.org/10.1016/j.biortech.2014.07.058

[12] H. Huaran, L. Hao and L. Feihu, "Seed germination of hemp (Cannabis sativa L.) cultivars responds differently to the stress of 
salt type and concentration", Industr. Crops Prod., vol. 123, pp. 254-261, 2018. https://doi.org/10.1016/j.indcrop.2018.06.089

[13] G. Ievinsh, "Review on physiological effects of vermicomposts on plants" in Biology of composts, M. K. Meghvansi and A. Varma, Eds. Cham (Switzerland): Springer Nature Switzerland, 2020, pp. 63-86. https://doi.org/10.1007/978-3-030-39173-7

[14] G. Ievinsh, U. Andersone-Ozola and S. Zeipina, "Comparison of the effects of compost and vermicompost soil amendments in organic production of four herb species", Biol. Agric. Hortic., vol.
36 ,
pp. 267-282, https://doi.org/10.1080/01448765.2020.1812116

[15] G. Ievinsh, M. Vikmane, A. Kirse and A. Karlsons, "Effect of vermicompost extract and vermicompost-derived humic acids on seed germination and growth of industrial hemp", Proc. Latv. Acad. Sci., Sect. B, vol. 71, pp. 286-292, 2017.

[16] A. Karlsons, A. Osvalde, U. Andersone-Ozola and G. Ievinsh, "Vermicompost from municipal sewage sludge affects growth and mineral nutrition of winter rye (Secale cereale) plants", J. Plant Nutr., vol. 39, pp. 765-780, 2016. https://doi.org/10.1080/01904167.2015.1087566

[17] S. Landi, R. Berni, G. Capasso, J.-F. Hausman, G. Guerriero and S. Esposito, "Impact of nitrogen nutrition on Cannabis sativa: an update on the current knowledge and future prospects", Int. J. Mol. Sci., vol. 20, article 5803, 2019. https://doi.org/10.3390/ijms20225803

[18] M. Mal̦ceva, M. Vikmane and V. Stramkale, "Changes of photosynthesis-related parameters and productivity of Cannabis sativa under different nitrogen supply", Environ. Exp. Biol., vol. 9, pp. 61-69, 2011. http://eeb.lu.lv/EEB/201108/EEB_9_Malceva.pdf

[19] A. Osvalde, "Optimization of plant mineral nutrition revisited: the roles of plant requirements, nutrient interactions, and soil properties in fertilization management", Environ. Exp. Biol., vol. 9, pp. 1-8, 2011. http://eeb.lu.lv/EEB/201108/EEB_9_Osvalde.pdf

[20] P. Papastylianou, I., Kakabouki and I. Travlos, "Effect of nitrogen fertilization on growth and yield of industrial hemp (Cannabis sativa L.)", Not. Bot. Horti Agrobot. Cluj-Napoca, vol. 46, pp. 197201, 2018. https://doi.org/10.15835/nbha46110862

[21] E. M. J. Salentijn, Q. Zhang, S. Amaducci, M. Yang and L. M. Trindade, "New developments in fiber hemp (Cannabis sativa L.) breeding", Industr. Crops Prod., vol. 68, 32-41, 2015. https://doi.org/10.1016/j.indcrop.2014.08.011
[22] R. Sausserde and A. Adamovics, "Industrial hemp for biomass production", J. Agric. Eng., vol. 44 (s2), article e123, 2013. https://doi.org/10.4081/jae.2013.365

[23] M. R. Schlemmer, D. D. Francis, J. F. Shanahan and J. S. Schepers, "Remotely measuring chlorophyll content in corn leaves with differing nitrogen levels and relative water content", Agron. J., vol. 97, pp. 106-112, 2005. https://doi.org/10.2134/agronj2005.0106

[24] J. R. Seemann, T. D. Sharkey, J. L. Wang and C. B. Osmond, "Environmental effects on photosynthesis, nitrogen-use efficiency, and metabolite pools in leaves of sun and shade plants", Plant Physiol., vol. 84, pp. 796-802, 1987. https://doi.org/10.1104/pp.84.3.796

[25] E. Small, T. Pocock and P. Cavers, "The biology of Canadian weeds. 119. Cannabis sativa L.", Can. J. Plant Sci., vol. 83, $217-$ 237, 2003. https://doi.org/10.4141/P02-021

[26] I. Stafecka, V. Stramkale, A. Stramkalis, I. Kroica and S. Ivanovs, "Impact of the agro-environmental factors on the seed yield and yields components productivity of Latvian original hemp", J. Res. Appl. Agric. Eng., vol. 61, pp. 164-167, 2016.

[27] R. J. Strasser, A. Srivastava and M. Tsimilli-Michael, "The fluorescence transient as a tool to characterise and screen photosynthetic samples" in Probing photosynthesis: mechanisms, regulation and adaptation, $\mathrm{M}$. Yunus, U. Pathre and P. Mohanty, Eds. London: CRC Press, 2000, pp. 445-483.

[28] K. Tang, P. C. Struik, S. Amaducci, T.-J. Stomph and X. Yin, "Hemp (Cannabis sativa L.) leaf photosynthesis in relation to nitrogen content and temperature: implications for hemp as a bioeconomically sustainable crop", GCB Bioenergy, vol. 9, 15731587, 2017. https://doi.org/10.1111/gcbb.12451

[29] K. Tang, P. C. Struik, X. Yin, C. Thouminot, M. Bjelková, V. Stramkale and S. Amaducci, "Comparing hemp (Cannabis sativa L.) cultivars for dual-purpose production under contrasting environments", Industr. Crops Prod., vol. 87, 33-44, 2016. https://doi.org/10.1016/j.indcrop.2016.04.026

[30] W. Wei, Y. Yan, J. Cao, P. Christie, F. Zhang and M. Fan, "Effects of combined application of organic amendments and fertilizers on crop yield and soil organic matter: An integrated analysis of longterm experiments", Agric. Ecosyst. Envrion., vol. 225, pp. 86-92, 2016. https://doi.org/10.1016/j.agee.2016.04.004

[31] L. Xiaozhai and R. C. Clarke, "The cultivation and use of hemp (Cannabis sativa L.) in ancient China", J. Int. Hemp Assoc., vol. 2, pp. 26-33, 1995. 